\title{
Griffithsin with A Broad-Spectrum Antiviral Activity by Binding Glycans in Viral Glycoprotein Exhibits Strong Synergistic Effect in Combination with A Pan-Coronavirus Fusion Inhibitor Targeting SARS-CoV-2 Spike S2 Subunit
}

\author{
Yanxing Cai ${ }^{1} \cdot$ Wei $\mathrm{Xu}^{1} \cdot{\text { Chenjian } \mathrm{Gu}^{1} \cdot \mathrm{Xia} \mathrm{Cai}^{1} \cdot \mathrm{Di} \mathrm{Qu}^{1} \cdot \mathrm{Lu} \mathrm{Lu}^{1} \cdot \text { Youhua Xie }^{1} \text { (D) Shibo Jiang }}^{1}$ (D)
}

Received: 12 August 2020 / Accepted: 10 September 2020/Published online: 14 October 2020

(c) Wuhan Institute of Virology, CAS 2020

\section{Dear Editor,}

The pandemic of coronavirus disease 2019 (COVID-19) caused by SARS-CoV-2 has posed a significant threat to global public health and economy, thus calling for the rapid development of effective therapeutics and prophylactics. Repurposing existing medicines with clinical safety profiles offers a more rapid hope of combating COVID-19 pandemic than developing a new therapeutic. For example, remdesivir was originally developed to treat Ebola virus infection and its safety to humans has been confirmed in a phase I clinical trial (Grein et al. 2020). Therefore, it immediately went to clinical trials for in vivo efficacy in treatment of COVID-19 patients after its in vitro antiSARS-CoV-2 activity was verified (Grein et al. 2020).

In this study, we tested the in vitro inhibitory activity of griffithsin (GRFT) against infection of pseudotyped and live SARS-CoV-2 infection, in order to repurpose the application of GRFT as a potential prophylactic or therapeutic to prevent or treat COVID-19. GRFT, a lectin isolated from the red alga Griffithsia sp, can recognize mannose with high affinity and has a broad-spectrum antiviral activity (Lusvarghi and Bewley 2016). GRFT is

Yanxing Cai, Wei Xu and Chenjian Gu have contributed equally to this work.

Electronic supplementary material The online version of this article (https://doi.org/10.1007/s12250-020-00305-3) contains supplementary material, which is available to authorized users.

Shibo Jiang

shibojiang@fudan.edu.cn

Youhua Xie

yhxie@fudan.edu.cn

1 Key Laboratory of Medical Molecular Virology (MOE/NHC/ CAMS), School of Basic Medical Sciences and BSL-3 Facility, Fudan University, Shanghai 200032, China safe to human as demonstrated in the phase I clinical trial of GRFT as an anti-HIV microbicide for prevention of sexual transmission of HIV in healthy populations, in which the single-dose open-label design and the multipledose, randomized design have been performed with treatment duration of 14 days and 30 subjects enrolled (Lee 2019).

We first performed SARS-CoV-2 pseudovirus infection assay (Xia et al. 2020) to evaluate the activity of GRFT against SARS-CoV-2 in vitro. As shown in Fig. 1A, GRFT could significantly inhibit SARS-CoV-2 pseudovirus infection in a dose-dependent manner with the half maximal inhibitory concentration $\left(\mathrm{IC}_{50}\right)$ of $293 \mathrm{nmol} / \mathrm{L}$. To further confirm this result, we then assessed its inhibitory activity against live SARS-CoV-2 infection with immunofluorescence and qRT-PCR assays. As shown in Fig. 1B and 1C, GRFT inhibited live SARS-CoV-2 infection in a dose-dependent manner with an $\mathrm{IC}_{50}$ of $63 \mathrm{nmol} / \mathrm{L}$, which is about 11 -fold more potent than remdesivir with half-maximal effective concentration of $0.77 \mu \mathrm{mol} / \mathrm{L}$ against SARS-CoV-2 infection (Wang et al. 2020). Moreover, we found that GRFT potently inhibited SARSCoV-2 S-mediated cell-cell fusion with an $\mathrm{IC}_{50}$ of $323 \mathrm{nmol} / \mathrm{L}$ (Fig. 1D). To the best of our knowledge, these results, for the first time, confirm that GRFT is able to inhibit SARS-CoV-2 infection in vitro.

To enter the host target cell, SARS-CoV-2 utilizes spike (S) protein to recognize the receptor angiotensin-converting enzyme 2 (ACE2) and eventually fuses viral membrane with host cell membrane, which makes $\mathrm{S}$ protein a promising target for developing antiviral drugs (Walls et al. 2020). SARS-CoV-2 S protein is extensively modified by $\mathrm{N}$-glycosylation with some glycosylation sites mainly occupied by oligomannose-type glycans, which can be recognized by mannose-binding proteins (Watanabe et al. 2020). It is found that mannose-binding proteins can inhibit infection of some 

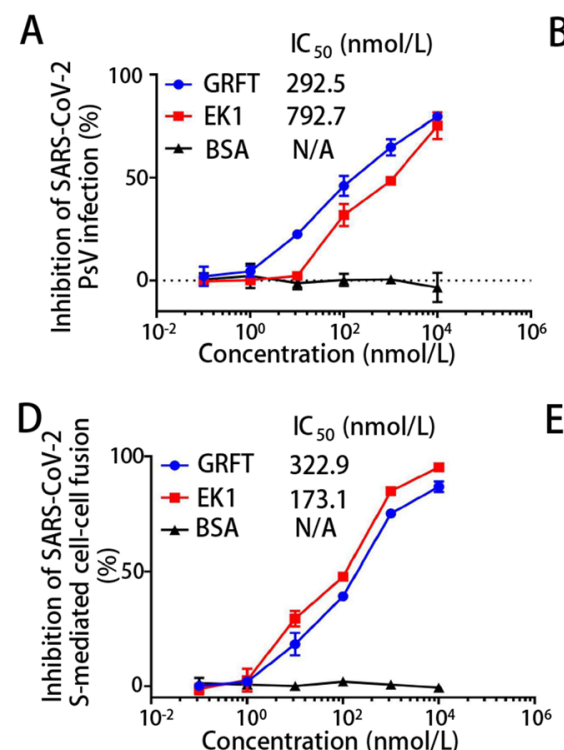

G
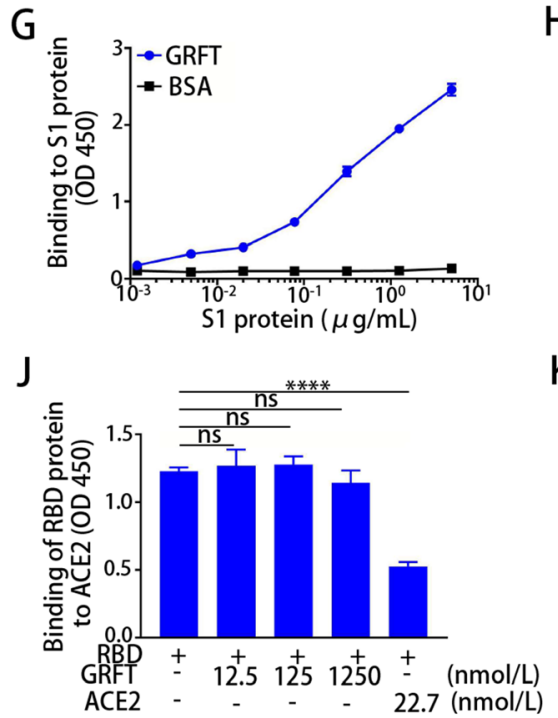

M

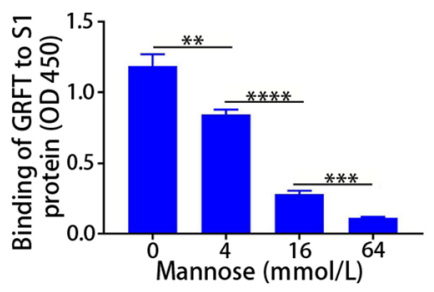

P

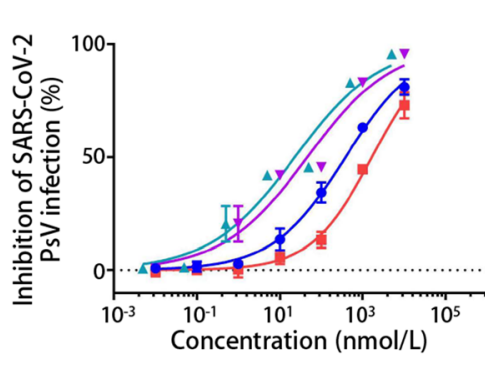

B

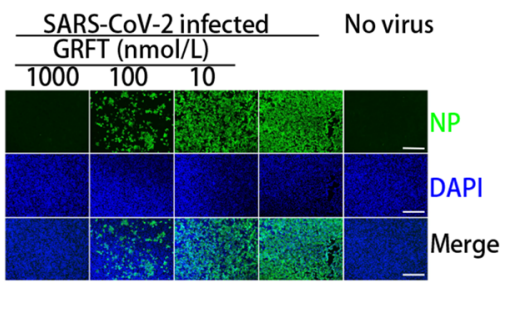

E

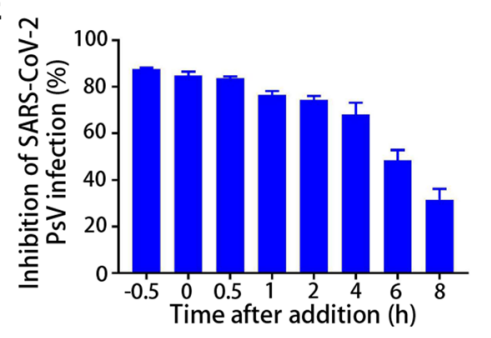

$\mathrm{H}$

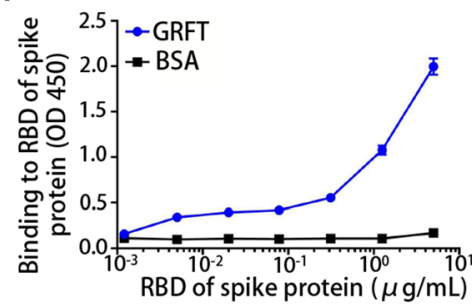

$\mathrm{K}$

HEK-293T cells
+ S1

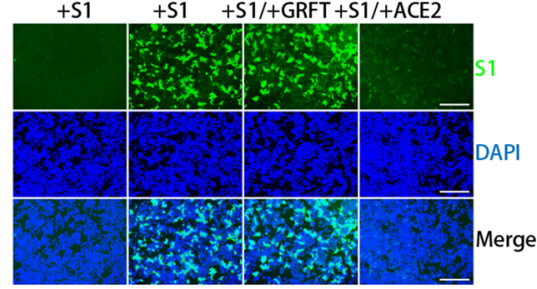

$\mathrm{N}$

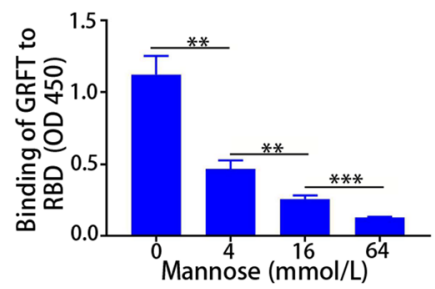

$\mathrm{IC}_{50}(\mathrm{nmol} / \mathrm{L})$

-GRFT alone $\quad 447.3$

-EK1 alone $\quad 987.9$

^GRFT in mixture 24.4

-EK1 in mixture $\quad 48.8$
C

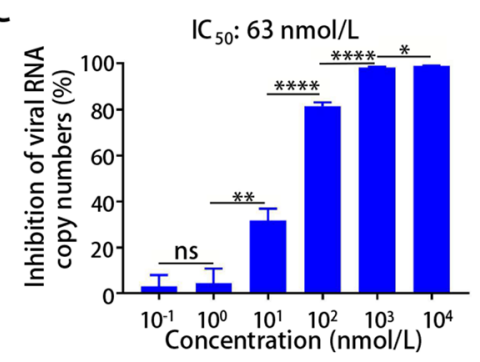

F

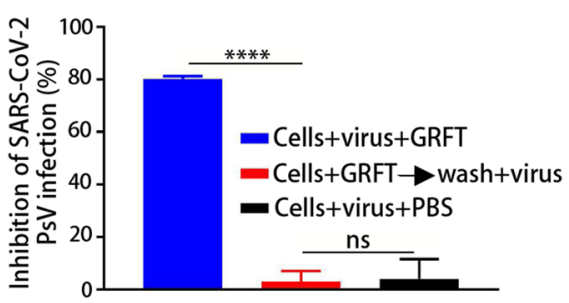

I

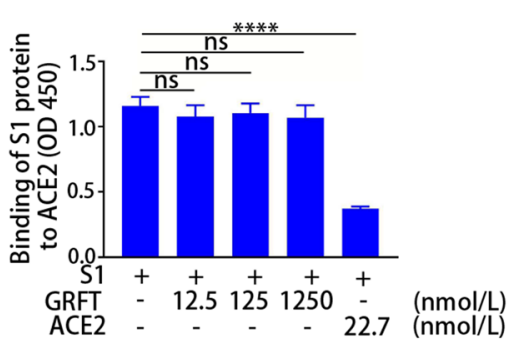

$\mathrm{L}$

HEK-293T cells HEK-293T/ACE2 cells

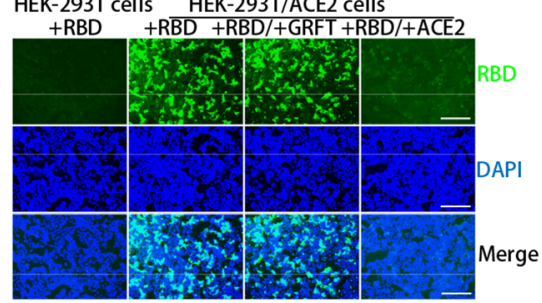

0

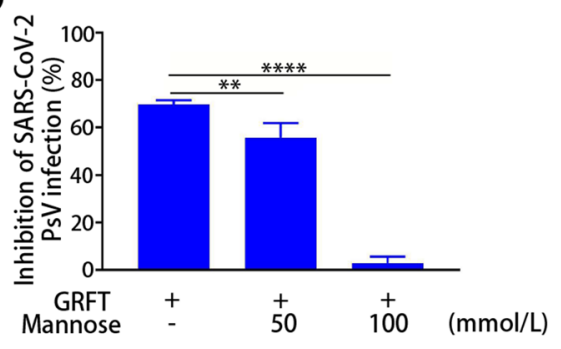


4Fig. 1 Inhibition of GRFT on SARS-CoV-2 infection and its mechanism of action. A-D GRFT inhibited infection of pseudotyped SARS-CoV-2 in HuH-7 cells measured by luciferase assay (A), and live SARS-CoV-2 (100 TCID 50$)$ in Vero-E6 cells measured by immunofluorescence assay (B), and qRT-PCR (C), as well as SARSCoV-2 S-mediated cell-cell fusion in $\mathrm{HuH}-7$ cells measured by immunofluorescence assay. Scale bars, $200 \mu \mathrm{m}$. (D). E-H Identification of the target site of GRFT. Time-of-addition assay (E). GRFT was added to HuH-7 cells $0.5 \mathrm{~h}$ before, during $(0 \mathrm{~h})$ and $0.5,1,2,4,6$, and $8 \mathrm{~h}$ after SARS-CoV-2 infection. After $12 \mathrm{~h}$ incubation, culture supernatant containing GRFT was replaced by fresh medium, followed by culture for $48 \mathrm{~h}$. The inhibitory activity of GRFT on SARS-CoV-2 pseudovirus infection was assessed by luciferase assay. Time-of-removal assay $(\mathbf{F})$. Binding of GRFT to $\mathrm{S} 1$ subunit $(\mathbf{G})$ and RBD (H) as measured by ELISA. I-L The effect of GRFT on the binding of S1 subunit (I) and RBD (J) to ACE2 as measured by ELISA, and on the binding of S1 subunit $(\mathbf{K})$ and RBD $(\mathbf{L})$ to HEK293 T/ACE2 cells as measured by immunofluorescence assay. Scale bars, $200 \mu \mathrm{m}$. M-O Effect of mannose on GRFT binding to S1 subunit (M) and RBD (N) measured by ELISA, and on GRFTmediated inhibition of SARS-CoV-2 pseudovirus infection $(\mathbf{O})$. $\mathbf{P}$ Inhibition of SARS-CoV-2 pseudovirus infection by GRFT alone, EK1 alone, and their combination. Statistical analysis was performed and calculated by GraphPad Prism 5.0. The CalcuSyn program (kindly provided by Dr. T. C. Chou) was used to calculate the synergistic effect of combinations using the median effect equation (Chou TC 2006). $* P<0.05$; $* * P<0.01$; $* * * P<0.001$; $* * * * P<0.0001$; ns, not significant. See supplementary materials for the details of all experiment

glycosylated viruses by directly binding to the glycans displayed on viral envelop protein (Lusvarghi and Bewley 2016).

To illustrate the antiviral mechanism of GRFT, we performed a time-of-addition assay to determine which stage in the virus life cycle might be affected by GRFT. As demonstrated in Fig. 1E, GRFT exhibited more than $80 \%$ inhibition of SARS-CoV-2 pseudovirus infection when GRFT were added $0.5 \mathrm{~h}$ before, during $(0 \mathrm{~h})$ and $0.5 \mathrm{~h}$ after SARS-CoV-2 pseudovirus infection, while the inhibitory activity was decreased to $32 \%$ when GRFT was added $8 \mathrm{~h}$ after SARS-CoV-2 pseudovirus infection. Next, we carried out a cell-based wash-out assay to determine whether GRFT acted on viruses or host cells. As shown in Fig. 1F, no inhibitory effect was found when GRFT was removed by washing the cells before addition of SARSCoV-2 pseudovirus, suggesting that GRFT acts on SARSCoV-2, rather than cells, at the early stage of virus entry. Considering that $\mathrm{S} 1$ subunit of $\mathrm{S}$ protein, which contains the receptor-binding domain (RBD), is the key component responsible for binding to the host cell (Lan et al. 2020), we next performed enzyme-linked immunosorbent assay (ELISA) to determine whether GRFT could bind to S1 subunit or RBD. As shown in Fig. $1 \mathrm{G}$ and $1 \mathrm{H}$, we found that GRFT could bind both S1 subunit and RBD.

We then investigated whether the binding of GRFT to S1 subunit or RBD could interfere with the interaction between S1 subunit or RBD and ACE2. As demonstrated in Fig. 1I and 1J, GRFT was unable to block the binding of S1 subunit or RBD to ACE2. To further confirm this result, we next assessed the effect of GRFT on the binding of S1 subunit or RBD to HEK-293T/ACE2 cells, a cell line stably expressing human ACE2, with HEK-293T cells as a control. As shown in Fig. $1 \mathrm{~K}$ and $1 \mathrm{~L}, \mathrm{~S} 1$ subunit and RBD could bind to HEK-293T/ACE2 cells, but not HEK-293T cells. Similarly, GRFT was unable to block the binding of S1 subunit and RBD to HEK-293T/ACE2 cells. These results suggest that although GRFT targets the SARS-CoV2 S1 subunit and RBD, it has no effect on the binding of S1 subunit and RBD to ACE2.

Since previous studies have reported that the glycans are the target of GRFT, we then performed ELISA to determine whether the binding of GRFT to S1 subunit and RBD is carbohydrate dependent. As shown in Fig. $1 \mathrm{M}$ and $1 \mathrm{~N}$, the binding of GRFT to S1 subunit and RBD were blocked by mannose in a dose-dependent manner. Next, we performed additional experiments to assess the effect of mannose on GRFT-mediated inhibition of SARS-CoV-2 pseudovirus infection. As shown in Fig. 1O, the inhibitory activity of GRFT against SARS-CoV-2 pseudovirus was attenuated by mannose, suggesting that GRFT inhibits SARS-CoV-2 infection by targeting the glycosylation sites in S1 subunit, possibly RBD, of SARS-CoV-2 S protein.

We have recently identified a pan-coronavirus fusion inhibitor, EK1, which is effective against all the human coronaviruses tested, such as SARS-CoV-2 and SARS-CoV (Xia et al. 2019, 2020). Here we assessed whether the combination of the broad-spectrum antiviral agent GRFT targeting glycans with the pan-CoV fusion inhibitor EK1 targeting HR1 domain of coronavirus S2 subunit has synergistic effects against SARS-CoV-2 pseudovirus infection. As showed in Fig. 1P, combining GRFT and EK1 exhibited strong synergistic effect, with a combination index (CI) of 0.103 , on SARS-CoV-2 pseudovirus infection with $\mathrm{IC}_{50}$ values of $447 \mathrm{nmol} / \mathrm{L}$ and $24 \mathrm{nmol} / \mathrm{L}$ when GRFT was tested alone and in combination, respectively ( $\sim 19$-fold of potency increase), and $988 \mathrm{nmol} / \mathrm{L}$ and $49 \mathrm{nmol} / \mathrm{L}$ when EK1 was tested alone and in combination, respectively ( $\sim 20$-fold of potency increase). These results suggest that because GRFT and EK1 have different target sites and mechanisms of action, their combination exhibits potent synergistic effect against SARS-CoV-2 infection and has a great potential to be used as a cocktail therapy for preventing and treating COVID-19.

In sum, this study has shown that GRFT is highly effective in inhibiting the pseudotyped and live SARSCoV-2 infection by binding to the glycosylation sites in the $\mathrm{S} 1$ subunit, possibly the RBD, of SARS-CoV-2 S protein, which is in consistent with the mechanism by which GRFT inhibits SARS-CoV infection (O'Keefe et al. 2010). Notably, combining GRFT with the pan-CoV fusion 
inhibitor EK1 exhibited excellent synergistic effect against SARS-CoV-2 pseudovirus infection. Given that GRFT can be easily manufactured in large quantities, it has a great potential to be further developed as a prophylactic or therapeutic, being used alone or in combination with EK1, in nasal spray or inhalation formulation to prevent or treat COVID-19, respectively. Moreover, considering the presence of SARS-CoV-2 in semen (Li et al. 2020) and possibility of sexual transmission of SARS-CoV-2, the existing GRFT microbicide gel may be a promising candidate for prevention of SARS-CoV-2 sextual transmission.

Acknowledgements This study was supported by the National Natural Science Foundation of China (81630090 and 81703571), the National Megaprojects of China for Major Infectious Diseases (2018ZX10301208 and 2018ZX10301403) and the Program of Shanghai Academic/ Technology Research Leader (20XD1420300).

\section{Compliance with Ethical Standards}

Conflict of interest The authors declare that they have no conflict of interest.

Animal and Human Rights Statement This article does not contain any studies with human or animal subjects performed by any of the authors.

\section{References}

Chou TC (2006) Theoretical basis, experimental design, and computerized simulation of synergism and antagonism in drug combination studies. Pharmacol Rev 58:621-681

Grein J, Ohmagari N, Shin D, Diaz G, Asperges E, Castagna A, Feldt T, Green G, Green ML, Lescure FX, Nicastri E, Oda R, Yo K, Quiros-Roldan E, Studemeister A, Redinski J, Ahmed S, Bernett J, Chelliah D, Chen D, Chihara S, Cohen SH, Cunningham J, D’Arminio Monforte A, Ismail S, Kato H, Lapadula G, L'Her E, Maeno T, Majumder S, Massari M, Mora-Rillo M, Mutoh Y,
Nguyen D, Verweij E, Zoufaly A, Osinusi AO, DeZure A, Zhao Y, Zhong L, Chokkalingam A, Elboudwarej E, Telep L, Timbs L, Henne I, Sellers S, Cao H, Tan SK, Winterbourne L, Desai P, Mera R, Gaggar A, Myers RP, Brainard DM, Childs R, Flanigan $T$ (2020) Compassionate use of remdesivir for patients with severe Covid-19. N Engl J Med 382:2327-2336

Lan J, Ge J, Yu J, Shan S, Zhou H, Fan S, Zhang Q, Shi X, Wang Q, Zhang L, Wang X (2020) Structure of the SARS-CoV-2 spike receptor-binding domain bound to the ACE2 receptor. Nature 581:215-220

Lee C (2019) Griffithsin, a highly potent broad-spectrum antiviral lectin from red algae: from discovery to clinical application. Mar Drugs 17:567

Li D, Jin M, Bao P, Zhao W, Zhang S (2020) Clinical Characteristics and results of semen tests among men with coronavirus disease 2019. JAMA 3:e208292

Lusvarghi S, Bewley CA (2016) Griffithsin: an antiviral lectin with outstanding therapeutic potential. Viruses 8:296

O'Keefe BR, Giomarelli B, Barnard DL, Shenoy SR, Chan PK, McMahon JB, Palmer KE, Barnett BW, Meyerholz DK, Wohlford-Lenane CL, McCray PB Jr (2010) Broad-spectrum in vitro activity and in vivo efficacy of the antiviral protein griffithsin against emerging viruses of the family Coronaviridae. J Virol 84:2511-2521

Walls AC, Park YJ, Tortorici MA, Wall A, McGuire AT, Veesler D (2020) Structure, function, and antigenicity of the SARS-CoV-2 spike glycoprotein. Cell 181:281-292

Wang M, Cao R, Zhang L, Yang X, Liu J, Xu M, Shi Z, Hu Z, Zhong W, Xiao G (2020) Remdesivir and chloroquine effectively inhibit the recently emerged novel coronavirus $(2019-\mathrm{nCoV})$ in vitro. Cell Res 30:269-271

Watanabe Y, Allen JD, Wrapp D, McLellan JS, Crispin M (2020) Site-specific glycan analysis of the SARS-CoV-2 spike. Science 369:330-333

Xia S, Liu M, Wang C, Xu W, Lan Q, Feng S, Qi F, Bao L, Du L, Liu S, Qin C, Sun F, Shi Z, Zhu Y, Jiang S, Lu L (2020) Inhibition of SARS-CoV-2 (previously 2019-nCoV) infection by a highly potent pan-coronavirus fusion inhibitor targeting its spike protein that harbors a high capacity to mediate membrane fusion. Cell Res 30:343-355

Xia S, Yan L, Xu W, Agrawal AS, Algaissi A, Tseng CK, Wang Q, Du L, Tan W, Wilson IA, Jiang S, Yang B, Lu L (2019) A pancoronavirus fusion inhibitor targeting the HR1 domain of human coronavirus spike. Sci Adv 5:eaav4580 